\title{
Surface Modification Reaction of Photocatalytic Titanium Dioxide with Triethoxysilane for Improving Dispersibility
}

\author{
Myung Jin Lee, Ji Ho Kim, and Young Tae Park* \\ Department of Chemistry, Keimyung University, Daegu 704-701, Korea. *E-mail: ytpark@kmu.ac.kr \\ Received January 23, 2010, Accepted March 18, 2010
}

\begin{abstract}
We have carried out the surface modification of photocatalytic $\mathrm{TiO}_{2}$ with triethoxysilane through dehydrogenation reaction and characterized the modified photocatalyst by spectroscopic methods, such as FT-IR, solid-state ${ }^{29} \mathrm{Si}$ MAS NMR, XPS, and XRF, etc. We also examined photocatalytic activity of the immobilized photocatalytic titanium dioxide with triethoxysilane by decolorization reaction of dyes such as cong red and methylene blue under visible light. Dispersion test showed that the photocatalytic titanium dioxide immobilized with triethoxysilane group has kept higher dispersibility than titanium dioxide itself. No appreciable precipitation takes place even after standing for $24 \mathrm{~h}$ in the 4:6 mixture ratio of ethanol and water.
\end{abstract}

Key Words: Titanium dioxide, Photocatalyst, Surface modification, Triethoxysilane, Characterization

\section{Introduction}

Photocatalytic titanium dioxide $\left(\mathrm{TiO}_{2}\right)$ has attracted considerable attention for their potential applications as a photocatalyst for decomposition of undesirable substances from environment and also as a water splitting reactions for hydrogen evolution. ${ }^{1}$ This phenomenon is based on the strong redox power of electron-hole pairs generated in catalytic $\mathrm{TiO}_{2}$ when its valence electrons are converted to conducting-band's electrons by photo irradiation. The reactive species created may interact with adsorbed water and oxygen to give radical species attacking the undesirable organic molecules. ${ }^{2-4}$

Extensive studies have been focused on increasing photocatalytic activity of titanium dioxide by doping with transition metal ions such as iron, vanadium, and gold, ${ }^{5-7}$ or with nonmetal elements such as carbon, ${ }^{8}$ boron, and nitrogen, ${ }^{9}$ and by entrapping with iodine in nanovoid-structured $\mathrm{TiO}_{2} .{ }^{10}$ Efficient dye sensitized solar cell was also achieved by photoinduced electron injection from a molecular excited-state into the conduction band of $\mathrm{TiO}_{2}$ film using phthalocyanine sensitizer. ${ }^{11}$

Recently, surface-modifications such as fluorination reac$\operatorname{tion}^{12}$ and solid-liquid reaction with hydride functional siloxane oil $^{13,14}$ have been reported in order to increase photocatalytic activity and photoinduced hydrophilicity of titanium dioxide, respectively. Functionalization of textile materials using modified titanium dioxide with aminotrimethoxysilane was also reported very recently. ${ }^{15}$ However, surface modification of $\mathrm{TiO}_{2}$ using alkoxyhydrosilanes has not yet been reported so far. The aim of this study is to prepare photocatalytic titanium dioxide surface-modified by triethoxysilanes and therefore in order to improve the dispersibility of immobilized titanium dioxide in a mixture solvent of water and ethanol.

Herein, we now report the coupling reactions of titanium dioxide with triethoxysilane $(\mathrm{EtO})_{3} \mathrm{Si}-\mathrm{O}-\mathrm{TiO}_{2}(3)$ through utilizing dehydrogenation in the presence of toluene as solvent. The photocatalytic materials immobilized with triethoxysilane were characterized by FT-IR and solid-state ${ }^{29}$ Si MAS NMR spectrophotometer in solid state as well as XPS, XRF, and XRD, etc. Furthermore, the new materials obtained can be expected to have photocatalytic activity under UV or visible light. In particular, we have carried out studying their characterization of the newly prepared photocatalytic titanium dioxide materials immobilized with triethoxysilane by using surface analysis technique and photocatalytic actvivity as well as dispersibility in polar solvents such as a mixture of water and ethanol.

\section{Results and Discussion}

Surface modification of photocatalytic $\mathrm{TiO}_{2}$ with triethoxysilane. Photocatalytic $\mathrm{TiO}_{2}$ (1) was prepared by the hydrolysis reaction of reagent-grade $\mathrm{TiCl}_{4}$ as precursor, neutralization of reaction mixture with ammonia, and then calcination of the precipitated material at $400{ }^{\circ} \mathrm{C}$ under oxygen atmosphere for 3 $\mathrm{h}$ following reported procedure. ${ }^{16}$ The prepared photocatalyst

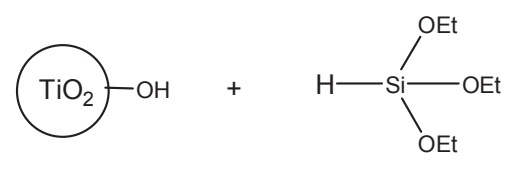

1
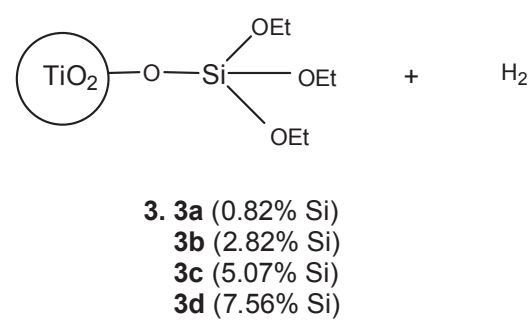


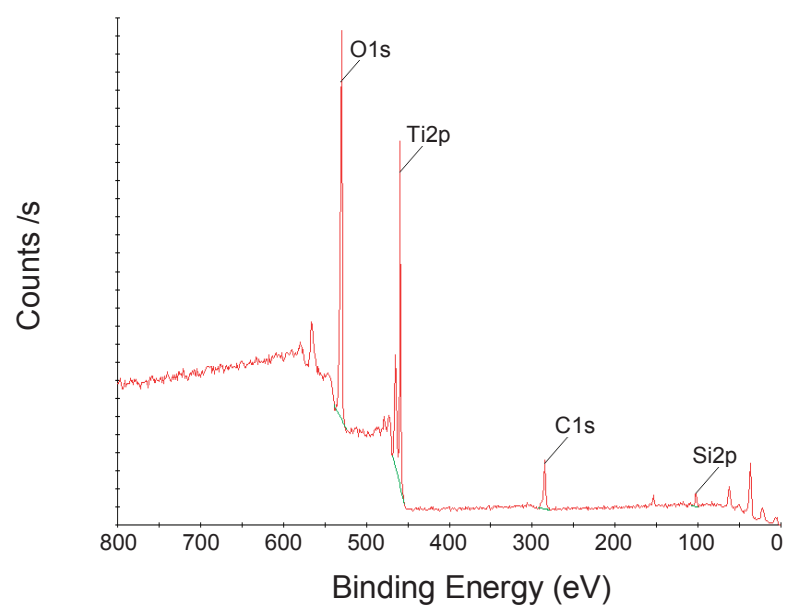

Figure 1. XPS survey spectrum of $\mathbf{3 a}$.

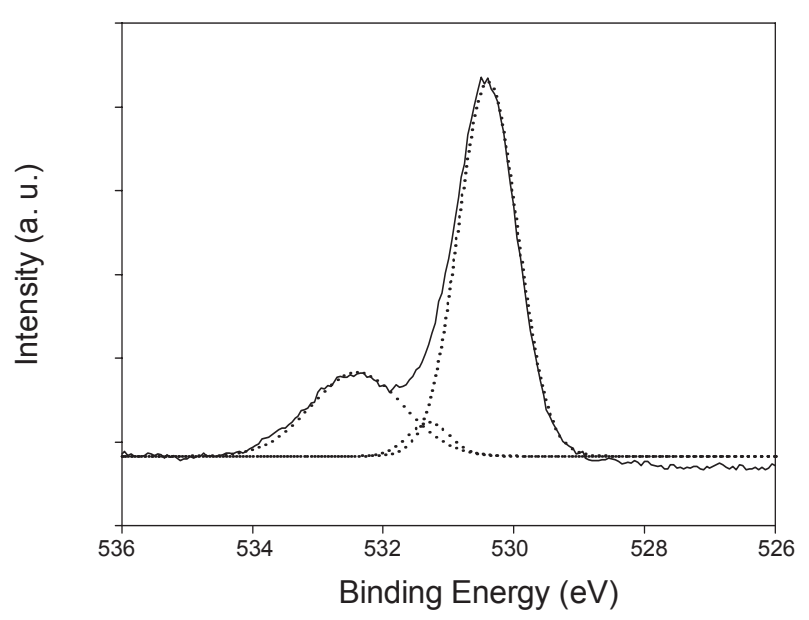

Figure 2. High-resolution XPS spectrum of the $\mathrm{O}$ 1s in $\mathbf{3 a}$ and its decomposition.

1 has the phase ratio of 75:25 in anatase and rutile according to XRD pattern, ${ }^{16}$ in which the mixture phase of anatase and rutile may cause a slight shift to longer wavelengths and extension of the absorption band in the visible region of UV-vis spectra compared to the anatase catalyst (vide infra).

As shown in Scheme 1, the surface modification reaction was carried out in dried toluene at $60{ }^{\circ} \mathrm{C}$ for $8 \mathrm{~h}$ under argon by the dehydrosilylation reactions of $\mathbf{1}$ with triethoxysilane (2) to yield the surface modified $\mathrm{TiO}_{2}$ 3a-d. ${ }^{17}$

Characterization of surface-modified $\mathrm{TiO}_{2}$. Firstly, the surface-modified photocatlytic $\mathrm{TiO}_{2}$ materials $\mathbf{3 a - d}$ have been characterized by X-ray fluorescence spectra (XRF). The quantitative elemental analysis by XRF indicated that the contents of $\mathrm{Si}$ atom in the surfaced-modified powder $\mathbf{3 a}, \mathbf{3 b}, \mathbf{3 c}$, and $\mathbf{3 d}$ were $0.82 \%, 2.82 \%, 5.07 \%$, and $7.56 \%$ by weights, respectively. The Fourier transform infrared (FT-IR) spectrum of $\mathbf{3 a}$ after washed with chloroform exhibits that the strong peaks between 1045 and $1115 \mathrm{~cm}^{-1}$ appear due to the $\mathrm{Si}-\mathrm{O}$ stretching vibration frequencies and the peaks at $2970 \mathrm{~cm}^{-1}$ due to the aliphatic $\mathrm{C}-\mathrm{H}$ stretching vibration motions, respectively. ${ }^{18,19}$ According to the FT-IR spectrum of $\mathbf{3 a}$ after washed with chloroform, the cha-

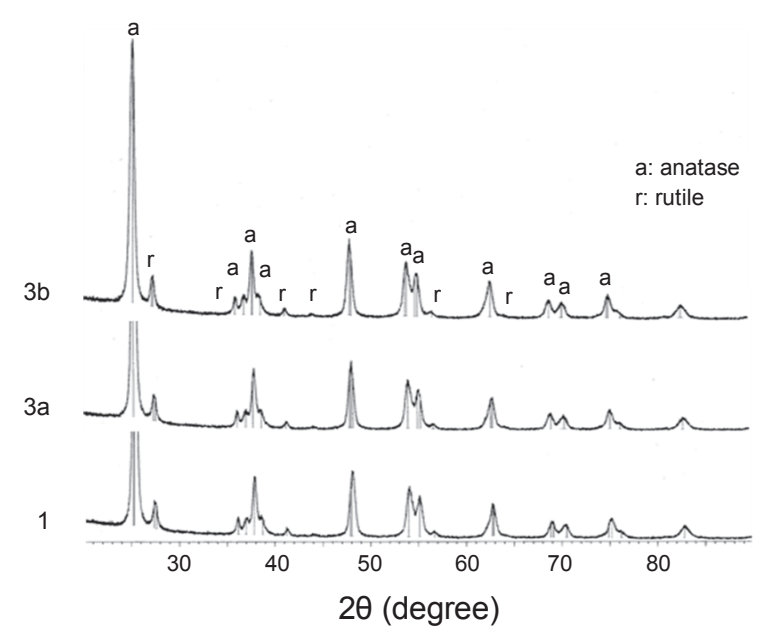

Figure 3. XRD patterns of $\mathbf{1}, \mathbf{3 a}$, and $\mathbf{3 b}$.

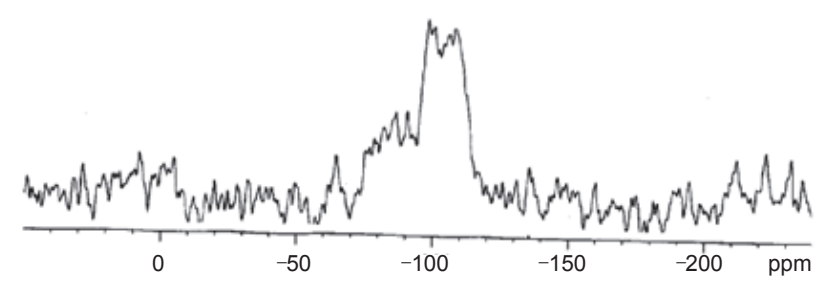

Figure 4. Solid-state ${ }^{29} \mathrm{Si}$ MAS NMR spectrum of $\mathbf{3 a}$

racteristic peak at around $2160 \mathrm{~cm}^{-1}$ attributed to the $\mathrm{Si}-\mathrm{H}$ stretching vibration frequency does not show up at all, ${ }^{18,19}$ suggesting that the dehydrosilylation reaction of $\mathbf{1}$ with $\mathbf{2}$ underwent completely under this reaction condition.

Figure 1 shows the X-ray photoelectron spectroscopy (XPS) survey spectrum of $\mathbf{3 a}$ after washed with chloroform. It contains $\mathrm{C} 1 \mathrm{~s}$ and $\mathrm{Si} 2 \mathrm{p}$ peaks as well as the Ti $2 \mathrm{p}_{3 / 2}$ and $\mathrm{O} 1 \mathrm{~s}$ peaks. The binding energies of $\mathrm{Ti}\left(2 \mathrm{p}_{3 / 2}\right), \mathrm{O}(1 \mathrm{~s}), \mathrm{Si}(2 \mathrm{p})$, and $\mathrm{C}(1 \mathrm{~s})$ are observed at 459.05, 530.63, 102.90, and $284.96 \mathrm{eV}$, respectively, which indicates the presence of the ethoxysilane group in the sample 3a. Furthermore, C 1 s and Si 2 p peaks along with the Ti $2 p_{3 / 2}$ and $O 1$ s peaks are also observed for all the samples 3b-c. Figure 2 shows the high-resolution XPS spectra of O $1 \mathrm{~s}$ peaks of $\mathbf{3 a}$ and its decomposition. The $\mathrm{O} 1 \mathrm{~s}$ region may be decomposed into three contributions, which is that the peaks at 530.4, 531.3, and 532.4 eV correspond to Ti-O in $\mathrm{TiO}_{2}$, hydroxyl groups $\left(\mathrm{OH}^{-}\right)$, and Ti-O-Si along with $\mathrm{Si}-\mathrm{O}-\mathrm{Et}$, respectively. ${ }^{14,20,2}$

As shown in Figure 3 of the X-ray diffraction (XRD) patterns of $\mathbf{1}, \mathbf{3} \mathbf{a}$ and $\mathbf{3 b}$, it is obvious that the modification reaction of dehydrosilation does not change the bulk crystal structure of prepared $\mathrm{TiO}_{2}$. Therefore the decrease or increase of the degradation reaction rate of dye on surface-modified $\mathrm{TiO}_{2}$ might be due to surface influence, including surface morphology change, defect and roughness increase, as well as reactant adsorption improvement, etc.

Figure 4 shows the solid-state ${ }^{29} \mathrm{Si}$ magic angle spinning nuclear magnetic resonance (MAS NMR) spectra of $\mathbf{3} \mathbf{a}$, in which a new ${ }^{29} \mathrm{Si}$ NMR peak is observed at between -90 and $-108 \mathrm{ppm}$ 

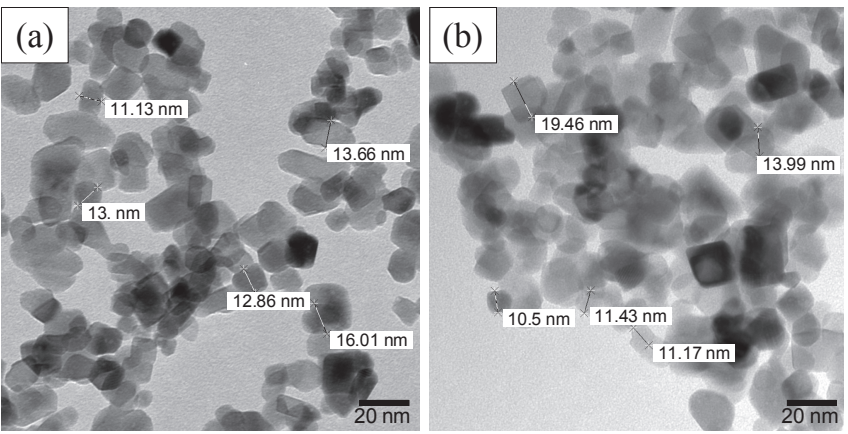

Figure 5. TEM images of (a) 1 and (b) $3 \mathbf{a}$.

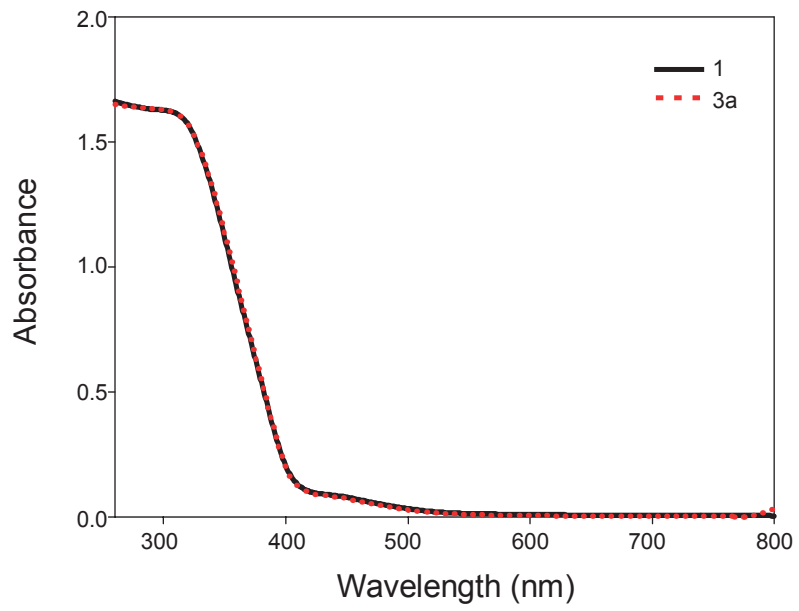

Figure 6. UV-vis spectra of $\mathbf{1}$ (solid line) and $\mathbf{3 a}$ (dotted line).

when compared with the resonance observed at -59 ppm for triethoxysilane 2 used as a reactant. According to the solid-state ${ }^{29} \mathrm{Si}$ MAS NMR spectra of $\mathbf{3 a}$, it also indicates clearly that the structure of 3a must contain a $\mathrm{Q}$ unit of silicon-modified $(\mathrm{EtO})_{3}$ $\mathrm{Si}-\mathrm{O}-\mathrm{TiO}_{2}$ on the surface of these particles. ${ }^{22}$

The particle sizes of $\mathbf{1}$ and $\mathbf{3 a}$ were analyzed by transmission electron microscopy (TEM). TEM images demonstrate the sizes of particle ranging from $11 \mathrm{~nm}$ to $20 \mathrm{~nm}$, as shown in Figure 5. While the particle size analyses by electron light scattering (ELS) in ethanol and water as solvents for 3a were turned out to be $82.9 \mathrm{~nm}$ and $156.4 \mathrm{~nm}$, respectively, the particle sizes of $3 \mathrm{~b}$ in ethanol and water were found to be $109.0 \mathrm{~nm}$ and $124.7 \mathrm{~nm}$, respectively. These results of particle size measured by using ELS are greater than those measured by TEM, probably due to the coagulation of photocatalytic $\mathrm{TiO}_{2}$ particle in solution states of these solvents.

As shown in Figure 6 of diffuse reflectance UV-vis absorption spectra of $\mathbf{1}$ and $\mathbf{3 a}$, the modification reaction of $\mathbf{1}$ by dehydrosilation does not change much the absorption of prepared $\mathrm{TiO}_{2}$. Diffuse reflectance UV-vis absorption spectra show a steep fall in absorbance observed from the absorption edge at $410 \mathrm{~nm}$ attributed to the interband transition. The onset absorption of the photocatalytic $\mathrm{TiO}_{2}$ is extrapolated to $3.02 \mathrm{eV}$ corresponding (a)

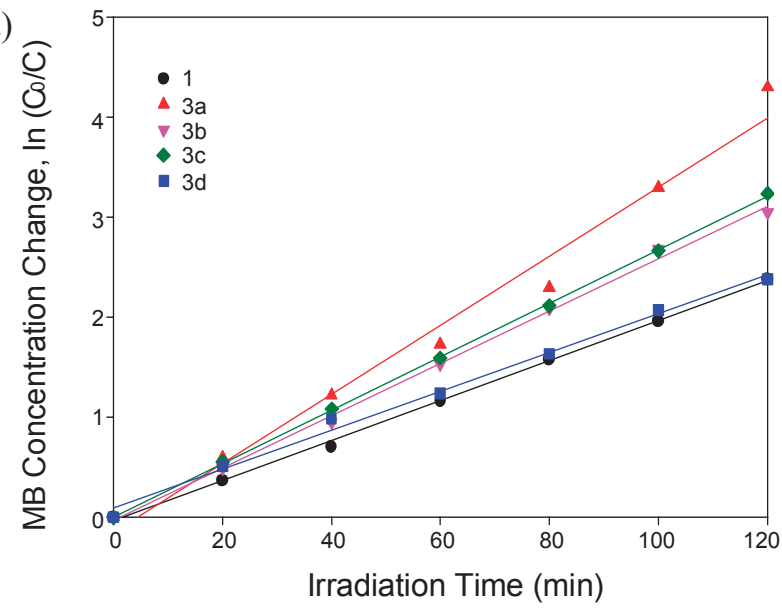

(b)

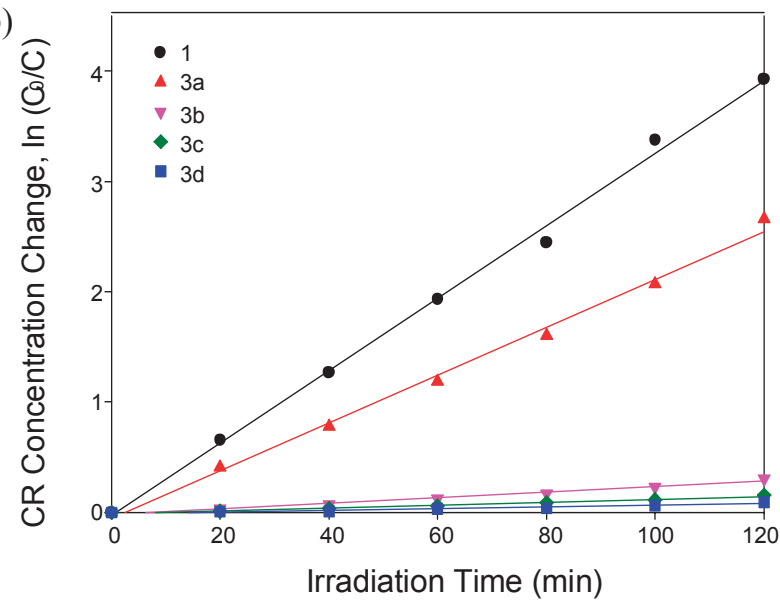

Figure 7. Photocatalytic activities of the samples $\mathbf{1}$ and 3a-d for (a) methylene blue (MB) and (b) congo red (CR) under visible light.

to the band-gap energy. ${ }^{23}$ It also exhibits a weak but significantly broadended band at longer wavelengths than $400 \mathrm{~nm}$ up to $532 \mathrm{~nm}$, which might be caused to absorb visible light due to the mixture phase ratio of 75:25 in anatase and rutile.

Photocatalytic properties and dispersion test. In order to study the photocatalytic properties of $\mathbf{1}$ and $\mathbf{3 a} \mathbf{a} \mathbf{d}$, decolorization reactions of congo red (CR) and methylene blue (MB) were carried out in aqueous solution containing the photocatalysts $\mathrm{TiO}_{2}$ under irradiation of visible light at room temperature. Figure 7 shows the comparison of photocatalytic decomposition of congo red and methylene blue on $\mathbf{1}$ and 3a-d with varying Si contents under visible light irradiation. In the case of MB, 3a-d shows better photocatalytic activity than $\mathbf{1}$. However, in the case of CR, 1 shows better photocatalytic activity than 3a-d. These results indicate that the optimum composition of $\mathrm{Si}$ atom might be around $0.82 \%$ by weight in the case of photocatlytic materials 3a-d for the photocatalytic activity of surface-modified $\mathrm{TiO}_{2}$ by using triethoxysilane.

We also tried to compare the dispersibility of $1.5 \%(\mathrm{w} / \mathrm{v})$ solutions of 3a with $\mathbf{1}$ in mixture solvent of water and ethanol, as shown in Figure 8. It clearly shows that $\mathbf{3 a}$ has higher dispersibility without appreciable precipitation than 1 even after standing for $24 \mathrm{~h}$ in the 4:6 mixture ratio solvent of ethanol and water. 
(a)

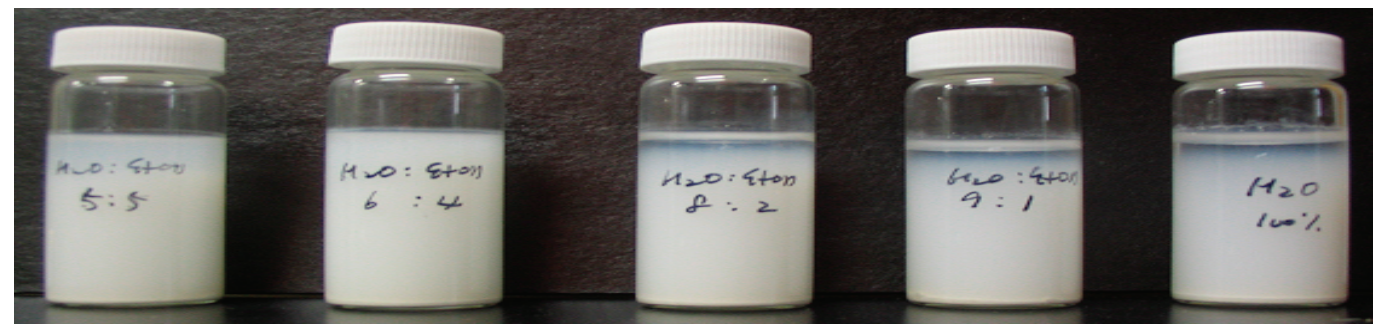

a-1

a-2

a-3

a-4

a-5

(b)

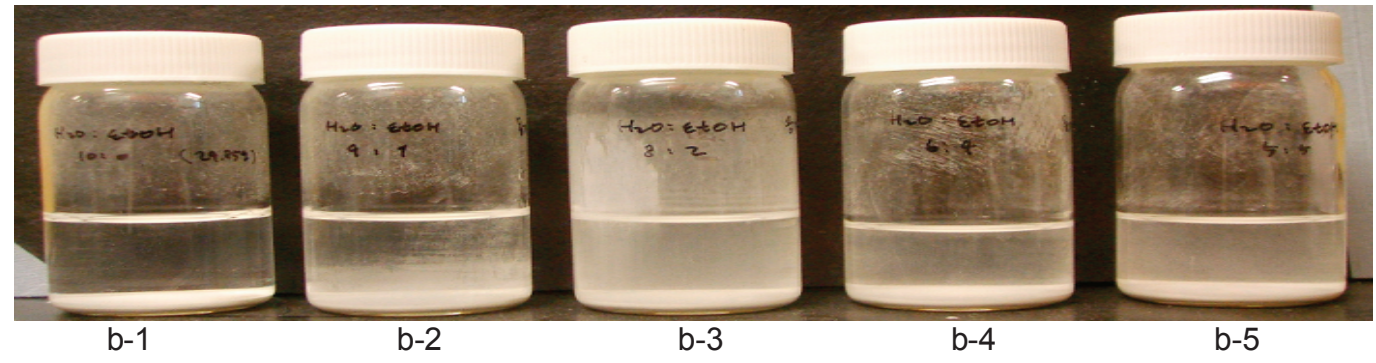

Figure 8. Dispersibility test comparison of (a) $1.5 \%$ (w/v) solutions of $\mathbf{3 a}$ and (b) $\mathbf{1}$ in mixture solvents of water and ethanol after standing for $24 \mathrm{~h}$. The mixture ratios of water and ethanol for a-1, a-2, a-3, a-4, and a-5 are 5:5, 6:4, 8:2, 9:1, and 10:0, respectively. The mixture ratios of water and ethanol for b-1, b-2, b-3, b-4, and b-5 are 10:0, 9:1, 8:2, 6:4, and 5:5, respectively.

\section{Conclusion}

We have successfully prepared the surface-modified photocatalytic $\mathrm{TiO}_{2}$ 3a-d by using triethoxysilane through dehydrogenation reaction, and characterized the modified photocatalyst by spectroscopic methods such as FT-IR, solid-state ${ }^{29} \mathrm{Si}$ MAS NMR, XPS, and XRF, etc. We also examined photocatalytic activity of the immobilized photocatalytic $\mathrm{TiO}_{2}$ with triethoxysilane by decolorization reaction of dyes such as cong red and methylene blue under visible light. Dispersibility test shows that the photocatalytic titanium dioxide immobilized with triethoxysilane group has kept better dispersed solution without appreciable precipitation than titanium dioxide itself even after $24 \mathrm{~h}$ in the 4:6 mixture ratio of ethanol and water.

\section{Experimental Section}

General procedures. All the chemicals were purchased from Aldrich Chemicals Inc. All solvent were purified prior to use according to standard literature methods: toluene was distilled from sodium benzophenone ketyl. ${ }^{24}$ All glassware was assembled and was then flame-dried while being swept with argon. Solid state ${ }^{29}$ Si MAS nuclear magnetic resonance (NMR) spectroscopy was performed on a Varian Unity INOVA 600 MHz FTNMR spectrometer at the Daegu Branch of the Korea Basic Science Institute. Fourier transform infrared (FR-IR) spectra were recorded on a Bruker IFS-48 FT-IR spectrometer using DRIFT method. Powder X-ray diffraction (XRD) patterns were recorded on Philips X'Pert APD diffractometer with $\mathrm{Cu} \mathrm{K} \alpha$ radiation. X-ray photoelectron spectroscopy (XPS) measurements were carried out on a VG Scientifics ESCALAB 250 spectrometer. X-ray fluorescence spectra (XRF) were recorded on Philips PW 2400 spectrometer. Transmission electron microscope (TEM) was conducted with a Hitachi H-7600. The sizes of prepared $\mathrm{TiO}_{2}$ particles were observed with electrophoretic light scattering (ELS) spectrophotometer using an Otuska ELS 8000 at the Chuncheon Branch of the Korea Basic Science Institute. Diffuse reflectance UV-vis absorption spectra in solid were collected by a Shimadzu UV-3101 PC spectrophotometer. UVvis absorption spectra in solution were also recorded by a Shimadzu UV-1601 spectrometer.

Photocatalytic $\mathrm{TiO}_{2}$ (1) was prepared by hydrolysis reaction of reagent-grade $\mathrm{TiCl}_{4}$ as precursor using ice-water bath, neutralization of the reaction mixture with ammonia water $(2.5 \mathrm{M})$, and then calcination of the precipitated material at $400{ }^{\circ} \mathrm{C}$ under oxygen atmosphere for $3 \mathrm{~h}$, according to the previously reported method. $^{16}$

Surface modification of $\mathrm{TiO}_{2}$ with triethoxysilane. A $100 \mathrm{~mL}$ round bottomed flask was equipped with a reflux condenser, a Teflon covered magnetic stirring bar, and heating mantle. The flask was charged with the prepared $\mathrm{TiO}_{2} 1(6.0 \mathrm{~g}, 75 \mathrm{mmol})$ (dried at $120^{\circ} \mathrm{C}$ for $2 \mathrm{~h}$ ), triethoxysilane $(2)(0.37 \mathrm{~g}, 2.3 \mathrm{mmol})$, and dried toluene $(20 \mathrm{~g})$ under an argon atmosphere. The reaction mixture was stirred at $60^{\circ} \mathrm{C}$ for $8 \mathrm{~h}$. After then, the solvent was removed by rotary evaporation. The crude product was washed with chloroform three times and dried at reduced pressure. In this way the purified product was obtained as a white powder 3a, $5.86 \mathrm{~g},{ }^{29} \mathrm{Si} \mathrm{CP} / \mathrm{MAS}$ NMR $(150 \mathrm{MHz}): \delta-90 \sim-108$; IR (DRIFT): $v 2970$ (-CH), 1254, 1115, 1045 (Si-O-C) cm ${ }^{-1}$; XPS (binding energy, eV): Ti $\left(2 \mathrm{p}_{3 / 2}, 459.05\right), \mathrm{O}(1 \mathrm{~s}, 530.63), \mathrm{Si}$ $(2 \mathrm{p}, 102.90), \mathrm{C}(1 \mathrm{~s}, 284.96)$. The content of Si atom in surfacemodified $\mathrm{TiO}_{2}$ powder 3a was $0.82 \%$ (by weight) determined by XRF. Surface modifications of $\mathbf{1}$ (6.0 g, $75 \mathrm{mmol})$ with 2 (1.23 g, $7.5 \mathrm{mmol}), 2$ (1.85 g, $11.3 \mathrm{mmol})$, and 2 (2.59 g, $15.8 \mathrm{mmol})$ were carried out in the same manner and the purified product as white powders $\mathbf{3 b}(5.72 \mathrm{~g}), \mathbf{3 c}(6.00 \mathrm{~g})$, and $\mathbf{3 d}$ (5.79 g) obtained, respectively. For $3 \mathbf{b}$, XPS (binding energy, eV): Ti ( $2 \mathrm{p}_{3 / 2}$, 458.87), O (1s, 530.18), Si (2p, 102.37), C (1s, 285.05). For 3c, XPS (binding energy, eV): Ti $\left(2 \mathrm{p}_{3 / 2}, 459.10\right), \mathrm{O}(1 \mathrm{~s}, 530.87), \mathrm{Si}$ $(2 \mathrm{p}, 103.25), \mathrm{C}(1 \mathrm{~s}, 284.69)$. The contents of Si atom in surface- 
modified $\mathrm{TiO}_{2}$ powders $\mathbf{3 b}, \mathbf{3 c}$, and $\mathbf{3 d}$ were $2.82 \%, 5.07 \%$, and $7.56 \%$ (by weights) determined by XRF, respectively. The XRD patterns and UV-vis spectra in the solid state as well as TEM images are described in Result and Discussion.

Measurement of photocatalytic activities. The photocatalytic activities of $\mathbf{1}$ and 3a-d were measured by decolorization reaction of congo red and methylene blue in aqueous solution containing the photocatalysts $\mathbf{1}$ and 3a-d under a $500 \mathrm{~W}$ highpressure mercury lamp irradiation with UV-filter. A $0.10 \mathrm{~g}$ portion of 1 or 3a-d was mixed with $200 \mathrm{~mL}$ of the aqueous congo red solution $(50 \mathrm{ppm})$ or methylene blue solution $(15 \mathrm{ppm})$ in optically matched Pyrex vessel, and the mixed solution was simultaneously irradiated with vigorous stirring using magnetic stirrer under visible light. After a certain period of irradiation, each solution was filtered by using $0.2 \mu \mathrm{m}$ membrane filter to remove the solid photocatalysts, followed by taking the filtrate solution to measure the absorption spectral change of congo red or methylene blue to monitor decolorization reaction.

Dispersion test. The dispersibility of $\mathbf{1}$ and $\mathbf{3 a - d}$ was compared by precipitation of the $\mathrm{TiO}_{2}$ particle in mixture solvent with the various ratios of water and ethanol. The photographs of dispersion solution and discussion are described in Result and Discussion.

Acknowledgments. This work was supported by the Program for the Training of Graduate Students in Regional Innovation which was conducted by the Ministry of Commerce Industry and Energy of the Korean Government and partly by the Keimyung University.

\section{References}

1. Fujishima, A.; Honda, K. Nature 1972, 238, 37.

2. Somorjai, G. A. Chemistry in Two Dimensions: Surface; Baker, G. F., Ed.; Cornell University Press: New York, 1981.

3. Childs, L. P.; Ollis, D. F. J. Catal. 1980, 66, 383.

4. Diebold, U. Surf. Sci. Rep. 2003, 48, 53.
5. Wang, X. H.; Li, J.-G.; Kamiyama, H.; Katada, M.; Ohashi, N.; Moriyoshi, Y.; Ishigaki, T. J. Am. Chem. Soc. 2005, 127, 10982.

6. Choi, H.-J.; Kim, J.-S.; Kang, M. Bull. Korean Chem. Soc. 2007 , 28,581 .

7. Li, H.; Bian, Z.; Zhu, J.; Huo, Y.; Li, H.; Lu, Y. J. Am. Chem. Soc. 2007, 129, 4538 .

8. Valentin, C. D.; Pacchioni, G.; Selloni, A. Chem. Mater. 2005, 17, 6656.

9. Asahi, R.; Morikawa, T.; Ohwaki, T.; Aoki, K.; Taga, Y. Science 2001, 293, 269.

10. Usseglio, S.; Damin, A.; Scarano, D.; Bordiga, S.; Zecchina, A.; Lamberti, C. J. Am. Chem. Soc. 2007, 129, 2822.

11. Morandeira, A.; Lopez-Duarte, I.; Martinez-Diaz, M. V.; O’Regan, B.; Shuttle, C.; Haji-Zainulabidin, N. A.; Torres, T.; Palomares, E.; Durrant, J. R. J. Am. Chem. Soc. 2007, 129, 9250.

12. Tang, J.; Quan, H.; Ye, J. Chem. Mater. 2007, 19, 116.

13. Nakabayashi, A. In Organosilicon Chemistry V. From Molecules to Materials; Auner, N., Weis, J. Eds.; Wiley-VCH Verlag GmbH \& Co. KGaA: Weinheim, Germany, 2003; p 819.

14. Zan, L.; Liu, Z.; Zhong, J.; Peng, Z. J. Mater. Sci. 2004, 39, 3261.

15. Sójka-Ledakowicz, J.; Lewartowska, J.; Kudzin, M.; Leonowicz, M.; Jesionowski, T.; Siwińska-Stefańska, K.; Krysztafkiewicz, A. J. Mater. Sci. 2009, 44, 3852.

16. Kim, S-M.; Yun, T-K.; Hong, D-I. J. Kor. Chem. Soc. 2005, 49, 567.

17. Kim, J. H.; Lee, M. J.; Yun, T. K.; Yun, S. B.; Jung, I. K.; Jung, J. W.; Park, Y. T. Repub. Korea patent KR 10-0871923, 27 Nov 2008, Appl. 2007-0052867, 30 May 2007.

18. Pretsch, E.; Bühlmann, P.; Affolter, C. In Structure Determination of Organic Compounds, Tables of Spectral Data, 3rd ed.; SpringerVerlag: Berlin, 2000.

19. Bellamy, L. J. In The Infra-red of Complex Molecules, 3rd ed.; John Wiley and Sons: New York, 1975.

20. Erdem, B.; Hunsicker, R. A.; Simmons, G. W.; Sudol, E. D.; Dimonie, V. L.; El-Asser, M. S. Langmuir 2001, 17, 2664.

21. Hwang Y. K.; Patil, K. R.; Kim, H.-K.; Sathaye, S. D.; Hwang, J.-S.; Park, S.-E.; Chang, J.-S. Bull. Korean Chem. Soc. 2005, 26,1515 .

22. Williams, E. In The Chemistry of Organic Silicon Compounds; Patai, S., Rappoport, Z., Eds.; John Wiley \& Sons: Avon, Great Britain, 1989; Part 1, Chapter 8.

23. Yoon, M.; Seo, M.; Jeong, C.; Jang, J. H.; Jeon, K. S. Chem. Mater. 2005, 17, 6069.

24. Armarego, W. L. F.; Perrin, D. D. Purification of Laboratory Chemicals, 4th ed.; Butterworth-Heinemann: Oxford, 1996. 